\title{
Correction to: Pluripotent trajectories: public oncology in Rwanda
}

\author{
Darja Djordjevic ${ }^{1,2}$ (D)
}

Published online: 24 July 2019

(C) Springer Nature Limited 2019

\section{Correction to: BioSocieties https://doi.org/10.1057/s41292-019-00160-w}

In the original publication of the article, the Acknowledgments section was omitted. The acknowledgements section and the revised author's biography are given in this Correction.

Acknowledgements I would like to thank Carlo Caduff, Jean Comaroff, John Comaroff, Paul Farmer, Michael Herzfeld, Arthur Kleinman, and Cecilia Van Hollen for their feedback on earlier versions of this text. I am also grateful for the comments from the three anononymous reviewers and the editors of BioSocieties.

Darja Djordjevic received her $\mathrm{PhD}$ in Anthropology from Harvard University, MD from Harvard Medical School, and Master 2 in Social Sciences from EHESS/ ENS Paris. She is currently a Resident Physician in Psychiatry at Yale School of Medicine, and a Research Associate at WiSER, Wits University, Johannesburg.

The original article can be found online at https://doi.org/10.1057/s41292-019-00160-w.

Darja Djordjevic

darja.djordjevic@yale.edu

1 Department of Psychiatry, Yale University School of Medicine, 300 George St, Suite \#901, New Haven, CT 06511, USA

2 Wits Institute for Social \& Economic Research, University of the Witwatersrand, Johannesburg, South Africa 
Publisher's Note Springer Nature remains neutral with regard to jurisdictional claims in published maps and institutional affiliations. 